\title{
Hemodialysis Associated with Severe and Unpredictable Hypoglycemia
}

\author{
Yuki Hisano ${ }^{1,2}$, Hideaki Kaneto ${ }^{2}$, Tomohiko Kimura ${ }^{2}$, Toru Ota ${ }^{1}$, Takayuki Kamao ${ }^{1}$, \\ Masatoshi Uno', Takaaki Mizushima ${ }^{1}$, Tomoatsu Mune ${ }^{2}$ and Kohei Kaku ${ }^{2}$
}

\begin{abstract}
We herein report the case of a 68-year-old man receiving hemodialysis who developed severe hypoglycemia. He became unconscious and exhibited a blood glucose level below $10 \mathrm{mg} / \mathrm{dL}$. We ruled out the possibility of other causes; however, severe hypoglycemia was observed even after starting glucose injections. The patient developed pneumonia and finally died. Although we conducted an autopsy, there were no specific findings explaining the severe hypoglycemia. We believe that carnitine deficiency was possibly involved in the severe hypoglycemia observed in this case. Physicians should be aware of the possibility of carnitine deficiency and/or severe hypoglycemia, especially in hemodialysis patients with malnutrition.
\end{abstract}

Key words: carnitine deficiency, hemodialysis, hypoglycemia

(Intern Med 55: 365-368, 2016)

(DOI: 10.2169/internalmedicine.55.4495)

\section{Introduction}

It is well known that hypoglycemia is induced by various causes and that severe hypoglycemia may lead to lifethreatening hypoglycemic coma $(1,2)$. Hypoglycemia is induced by the overuse of anti-diabetic drugs and/or insulin. In addition, hypoglycemia is caused by various diseases, including insulinoma, insulin autoimmune syndrome and adrenal insufficiency. Subjects suffering from hypoglycemia usually notice warning symptoms, such as cold sweating and/or palpitations; however, they may be unaware of their condition, without any symptoms. We herein report a case of severe and unpredictable hypoglycemia.

\section{Case Report}

We herein report the case of a 68-year-old man who developed severe hypoglycemia. The patient was diagnosed with type 2 diabetes at 54 years of age and started receiving hemodialysis at 64 years of age. He was treated with insulin and often experienced hypoglycemia. At 66 years of age, his glycemic control was gradually ameliorated and he stopped receiving insulin therapy according to the suggestion of the physician in charge. Thereafter, he did not use any antidiabetic drugs or insulin. However, he continued to often experience hypoglycemia, especially before undergoing hemodialysis. He experienced appetite loss, and his food intake was limited for several years. Indeed, his body mass decreased from $47.0 \mathrm{~kg}$ to $41.3 \mathrm{~kg}$ and his BMI decreased from $19.6 \mathrm{~kg} / \mathrm{m}^{2}$ to $17.2 \mathrm{~kg} / \mathrm{m}^{2}$ over four years.

One morning at 68 years of age, the patient's wife noticed that he was unconscious in bed, and he was immediately hospitalized. On admission, his height was $155 \mathrm{~cm}$ and his weight was $41.3 \mathrm{~kg}$. His body temperature was $35.3^{\circ} \mathrm{C}$, his blood pressure was $180 / 100 \mathrm{mmHg}$ and his heart rate was $88 / \mathrm{min}$. At that time, the blood glucose level was very low $(<10 \mathrm{mg} / \mathrm{dL}$ ), as was the serum insulin level (immunoreactive insulin (IRI) $<1.0 \mu \mathrm{U} / \mathrm{mL}$ ). In addition, there were several abnormalities indicating pancytopenia, renal dysfunction and malnutrition (Table 1,2). The total cholesterol level was low $(53 \mathrm{mg} / \mathrm{dL})$, presumably due to malnutrition. Chest and abdominal computerized tomography (CT) showed no lesions, which made us suspect malignancy in the chest and abdomen. On brain CT, there were no abnormalities in the brain. Furthermore, the patient did not take

${ }^{1}$ Department of Internal Medicine, Kaneda Hospital, Japan and ${ }^{2}$ Division of Diabetes, Metabolism and Endocrinology, Kawasaki Medical School, Japan

Received for publication November 12, 2014; Accepted for publication May 25, 2015

Correspondence to Dr. Yuki Hisano, hisano@med.kawasaki-m.ac.jp 
Table 1. Laboratory Findings on Admission.

\begin{tabular}{|c|c|c|c|c|c|}
\hline $\begin{array}{l}\text { Complete blood } \\
\text { cell count }\end{array}$ & & $\begin{array}{c}\text { Blood } \\
\text { biochemistry }\end{array}$ & & & \\
\hline WBC & $4,300 / \mu \mathrm{L}$ & $\mathrm{TP}$ & $5.4 \mathrm{~g} / \mathrm{dL}$ & BG & $<10 \mathrm{mg} / \mathrm{dL}$ \\
\hline $\mathrm{Neu}$ & $86.0 \%$ & Alb & $2.9 \mathrm{~g} / \mathrm{dL}$ & $\mathrm{HbA1c}$ & $4.1 \%$ \\
\hline Eos & $0.0 \%$ & Glb & $2.5 \mathrm{~g} / \mathrm{dL}$ & Total ketone body & $27.8 \mu \mathrm{mol} / \mathrm{L}$ \\
\hline Baso & $0.0 \%$ & T-bil & $0.6 \mathrm{mg} / \mathrm{dL}$ & AcAc & $14.3 \mu \mathrm{mol} / \mathrm{L}$ \\
\hline Mono & $3.0 \%$ & ALP & $256 \mathrm{IU} / \mathrm{L}$ & 3-OHBA & $13.5 \mu \mathrm{mol} / \mathrm{L}$ \\
\hline Lymph & $11.0 \%$ & AST & 39 IU/L & & \\
\hline $\mathrm{RBC}$ & $251 \times 10^{4} / \mu \mathrm{L}$ & ALT & $17 \mathrm{IU} / \mathrm{L}$ & $\mathrm{Na}$ & $144 \mathrm{mEq} / \mathrm{L}$ \\
\hline $\mathrm{Hb}$ & $8.4 \mathrm{~g} / \mathrm{dL}$ & $\gamma$-GTP & $21 \mathrm{IU} / \mathrm{L}$ & K & $3.3 \mathrm{mEq} / \mathrm{L}$ \\
\hline $\mathrm{Ht}$ & $25.8 \%$ & Cre & $3.53 \mathrm{mg} / \mathrm{dL}$ & $\mathrm{Cl}$ & $110 \mathrm{mEq} / \mathrm{L}$ \\
\hline \multirow[t]{4}{*}{ Plt } & $5.9 \times 10^{4} / \mu \mathrm{L}$ & BUN & $23 \mathrm{mg} / \mathrm{dL}$ & $\mathrm{P}$ & $3.3 \mathrm{mg} / \mathrm{dL}$ \\
\hline & & UA & $3.0 \mathrm{mg} / \mathrm{dL}$ & $\mathrm{Ca}$ & $7.9 \mathrm{mg} / \mathrm{dL}$ \\
\hline & & Amy & $17 \mathrm{U} / \mathrm{L}$ & CRP & $1.44 \mathrm{mg} / \mathrm{dL}$ \\
\hline & & Tchol & $53 \mathrm{mg} / \mathrm{dL}$ & & \\
\hline
\end{tabular}

Table 2. Endocrinological Data.

\begin{tabular}{llll}
\hline IRI & $<1.0 \mu \mathrm{U} / \mathrm{mL}$ & TSH & $3.81 \mu \mathrm{IU} / \mathrm{mL}$ \\
s-CPR & $0.2 \mathrm{ng} / \mathrm{mL}$ & FT3 & $<1.00 \mathrm{pg} / \mathrm{mL}$ \\
ACTH & $82.8 \mathrm{pg} / \mathrm{mL}$ & FT4 & $1.01 \mathrm{ng} / \mathrm{dL}$ \\
cortisol & $23.3 \mu \mathrm{g} / \mathrm{dL}$ & $\mathrm{GH}$ & $25.1 \mathrm{ng} / \mathrm{mL}$ \\
adrenaline & $49 \mathrm{pg} / \mathrm{mL}$ & IGF-1 & $31 \mathrm{ng} / \mathrm{mL}$ \\
noradrenaline & $828 \mathrm{pg} / \mathrm{mL}$ & glucagon & $131 \mathrm{pg} / \mathrm{mL}$ \\
dopamine & $337 \mathrm{pg} / \mathrm{mL}$ & anti-insulin antibody & $34.8 \%$ \\
aldosterone & $57.1 \mathrm{pg} / \mathrm{mL}$ & free insulin & $<3.0 \mu \mathrm{U} / \mathrm{mL}$ \\
renin & $0.1 \mathrm{ng} / \mathrm{mL} / \mathrm{h}$ & total insulin & $4 \mu \mathrm{U} / \mathrm{mL}$ \\
\hline
\end{tabular}

any drugs, such as antibiotics, new quinolones or the antiarrhythmic agent cibenzoline, both of which are known to induce hypoglycemia.

Based on these findings, we ruled out the possibility of the exogenous administration of insulin or other antidiabetic drugs, insulinoma, insulin autoimmune syndrome and adrenal insufficiency as underlying causes. The patient once became conscious following glucose injection, and severe hypoglycemia was often observed even after starting glucose treatment (Figure a, b). Several days after admission, he developed pneumonia, and his general condition gradually deteriorated. We administered the best possible treatment; however, he unfortunately died of heart failure in addition to pneumonia. In order to explore the cause of death and determine the pathogenesis underlying the severe hypoglycemia, we conducted an autopsy after obtaining the consent of his family. The findings obtained at autopsy were as follows: heart, no infarction or inflammation; lungs, neutrophilic infiltration compatible with the findings of pneumonia; liver, fibrosis in the portal and central venous regions; pancreas, atrophy of acinar cells compatible with chronic pancreatitis; no abnormalities in islets; kidneys, nodular lesions in the glomeruli compatible with diabetic renal failure; hypothalamus and pituitary gland, no pathological changes. On immunostaining for adrenocorticotropic hormone $(\mathrm{ACTH})$, growth hormone $(\mathrm{GH})$, prolactin, thyroidstimulating hormone (TSH), luteinizing hormone (LH) and follicle-stimulating hormone (FSH), there were no deficiencies in the hormone expression in the pituitary gland. In contrast, the patient's adipose tissue was severely atrophic and colloidal throughout his body, which strongly suggested malnutrition. In the bone marrow, there was a mixture of normocellular and gelatinous bone marrow, which also indicated malnutrition. There were no lesions suspicious of malignancy or insulin-like growth factor (IGF)-II-producing tumors, which are known to induce hypoglycemia $(3,4)$. Taken together, there were no specific findings that could explain the severe hypoglycemia.

It is known that reductions in carnitine production due to renal failure and the removal of carnitine via hemodialysis may lead to carnitine deficiency and subsequent hypoglycemia. In order to explore the cause of the patient's severe hypoglycemia, we examined the serum carnitine level, which was found to be very low: total carnitine $39.4 \mu \mathrm{mol} / \mathrm{L}$ (normal range: $45-91 \mu \mathrm{mol} / \mathrm{L}$ ), free carnitine $27.9 \mu \mathrm{mol} / \mathrm{L}$ (36-74 $\mu \mathrm{mol} / \mathrm{L})$. We therefore concluded that carnitine deficiency was presumably involved in the onset of severe hypoglycemia in this subject.

\section{Discussion}

To the best of our knowledge, the hypoglycemia observed in the current patient involves one of the most severe cases. The precise pathogenesis remains unclear; however, it is possible that carnitine deficiency due to long-term malnutrition and hemodialysis led to severe hypoglycemia in this case. In our patient, severe hypoglycemia was often observed, including after starting glucose injections. Although speculative, we assume that carnitine deficiency was involved in the onset of hypoglycemia because we seldom observe such severe and repeated cases of hypoglycemia, even in subjects with malnutrition and/or treatment with hemodialysis. There are several reports showing hypoglycemia in subjects with renal failure (5-7), although there are few reports discussing the reason for the hypoglycemia. There are also several reports of carnitine deficiency in subjects under hemodialysis. Indeed, it has been shown that the carnitine level decreases after a longer duration of hemodialysis, reaching approximately $26 \mathrm{mmol} / \mathrm{L}$ (8). However, such severe hypoglycemia, as that observed in the current patient, has been not found in subjects treated with hemodialysis. Therefore, we think that carnitine deficiency in addition to 

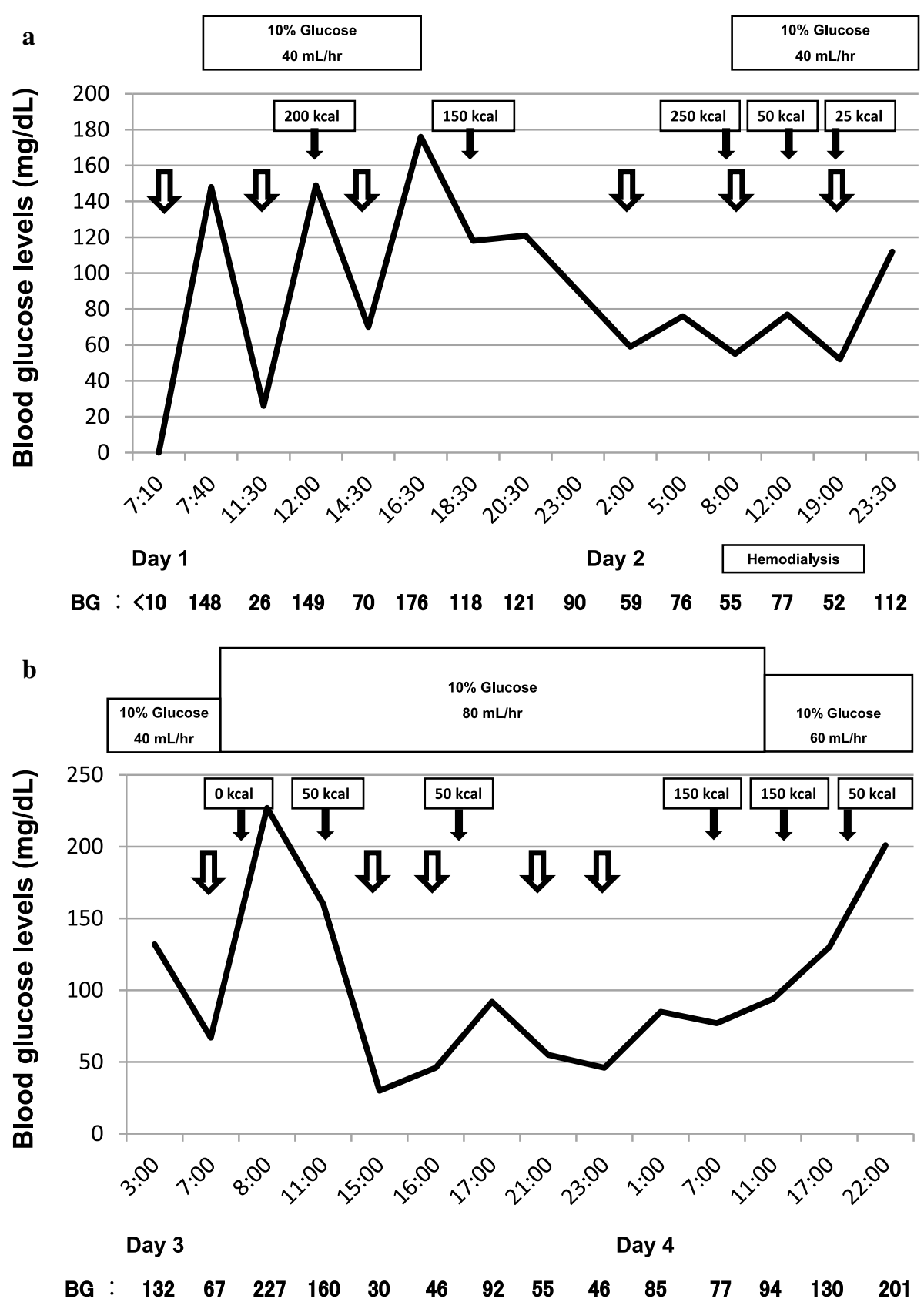

Figure. Blood glucose levels on day $1 \&$ day 2 (a) and day 3 \& day 4 (b) after admission. Open arrow: intravenous injection of $40 \mathrm{~mL}$ of $50 \%$ glucose. Close arrow: breakfast, lunch and supper. Numbers in rectangles: calorie intake at each meal

various other factors were involved in the onset of severe hypoglycemia in this case.

First, our patient had a history of drinking, although he did not drink for four years after the start of hemodialysis therapy. Therefore, we assume that his drinking per se did not directly lead to the onset of severe hypoglycemia, but rather that his history of drinking might have also been involved in the onset of hypoglycemia via an impaired liver function. Second, the glucagon response to hypoglycemia was very poor in this subject. It is known that repeated hypoglycemia leads to a poor glucagon response to hypoglycemia. Therefore, we believe that the current patient's poor glucagon response was presumably due to repeated hypoglycemia; however, we assume that the poor glucagon response alone did not cause the severe hypoglycemia observed in this subject, but rather that the poor glucagon response might have been one causative factor. Finally, we think that carnitine deficiency, which led to appetite loss and malnutrition, also facilitated the onset of severe hypoglycemia. In addition, the inability to release glycogen secondary to vitamin B6 and chromium deficiency may also lead to hypoglycemia, although we failed to measure the serum levels of vitamin B or chromium in this subject.

The autopsy findings revealed that our patient had fibrosis in the portal and central venous regions of the liver in addition to atrophy of acinar cells, compatible with pancreatitis, suggesting that impaired gluconeogenesis due to liver disease and severe malnutrition were also involved in the onset 
of severe hypoglycemia in this case. However, there have been no previous reports showing that the presence of such diseases alone leads to such severe hypoglycemia $(<10 \mathrm{mg}$ ) $\mathrm{dL}$ ) as that observed in the current case. Therefore, we assume that some other factors were also involved in the onset of severe hypoglycemia in our patient. Gluconeogenesis occurs in the liver as well as the kidney (9) and thus a reduction of gluconeogenesis in the kidney is a possible mechanism of hypoglycemia in subjects with renal failure. Moreover, carnitine production is reduced due to renal failure and carnitine is removed via hemodialysis. In addition, the carnitine levels in tissues as well as the serum are gradually decreased in hemodialysis subjects, a process thought to be involved in the reduction of gluconeogenesis $(10,11)$. The current patient received hemodialysis for four years, and thus we assume that the serum carnitine level gradually decreased, although we did not measure the time course of the carnitine level in this case.

It is known that, in cases in which the blood glucose level is high before hemodialysis, there is a large difference between the blood glucose level in the patient and the glucose concentration in the dialysis fluid, which leads to hypoglycemia during and/or after hemodialysis. In the current case, however, we used dialysis buffer containing $100 \mathrm{mg} / \mathrm{dL}$ of glucose, which was similar to the blood glucose level noted before hemodialysis. Therefore, we do not consider it likely that such alterations in the glucose level led to the severe hypoglycemia seen in this subject.

There are no reports showing that carnitine deficiency leads to severe hypoglycemia, as observed in this case. It has been reported, however, that severe hypoglycemia is detected in carnitine-deficient mice, leading to severe appetite loss and finally death (12). It has also been reported that a long period of treatment with carnitine increases the serum protein and albumin levels in subjects treated with hemodialysis (13). We think that the use of carnitine treatment in the early stage in this case might have prevented the patient's appetite loss and subsequent progression of malnutrition and onset of severe hypoglycemia. In addition, in order to explore the implications of carnitine deficiency in the onset of hypoglycemia, we should have examined the effects of carnitine therapy in the current case.

We ruled out all conceivable causes of hypoglycemia, including the exogenous administration of insulin or other anti-diabetic drugs, insulinoma, insulin autoimmune syndrome and adrenal insufficiency. It is noted, however, that we cannot exclude the possibility that some other factors, such as malnutrition, a history of drinking, poor glucagon response to hypoglycemia and impaired gluconeogenesis in the liver and kidney, were also involved in the onset of the severe and unpredictable hypoglycemia observed in this hemodialysis subject. Therefore, it might be safer to conclude that carnitine deficiency is a possible cause that may explain our patient's hypoglycemia. In conclusion, physicians should be aware of the possibility of severe hypoglycemia due to carnitine deficiency, especially in hemodialysis subjects with malnutrition, as this complication may lead to life-threatening hypoglycemic coma, as observed in the current case.

\section{The authors state that they have no Conflict of Interest (COI).}

\section{References}

1. The Diabetes Control and Complications Trial Research Group. Hypoglycemia in the diabetes control and complications trial. Diabetes 46: 271-286, 1997.

2. Home P, Riddle M, Cefalu WT, et al. Insulin therapy in people with type 2 diabetes: opportunities and challenges? Diabetes Care 37: 1499-1508, 2014.

3. Fukuda I, Hizuka N, Ishikawa Y, et al. Clinical features of insulinlike growth factor-II producing non-islet-cell tumor hypoglycemia. Growth Horm IGF Res 16: 211-216, 2006.

4. de Groot JW, Rikhof B, Van Doorn J, et al. Non-islet cell tumorinduced hypoglycemia: a review of the literature including two new case. Endocr Relat Cancer 14: 979-993, 2007.

5. Fisher KF, Lees JA, Newman JH. Hypoglycemia in hospitalized patients. N Engl J Med 315: 1245-1250, 1986.

6. Haviv YS, Sharkia M, Safadi R. Hypoglycemia in patients with renal failure. Ren Fail 22: 219-223, 2000.

7. Frizzel M, Larsen PR, Field JB. Spontaneous hypoglycemia associated with chronic renal failure. Diabetes 22: 493-498, 1977.

8. Sakurauchi Y. Effects of L-carnitine supplementation on muscular symptoms in hemodialyzed patients. Am J Kidney Dis 32: 258264, 1998.

9. Owen OE, Felig P, Morgan AP, et al. Liver and kidney metabolism during prolong starvation. J Clin Invest 48: 574-583, 1969.

10. Leschke M, Rumpf W, Eisenhauer T, et al. Quantitative assessment of carnitine loss during hemodialysis and hemofiltration. Kidney Int 32: S132, 1983.

11. Hiatt WR, Koziol BJ, Shaprio JI, et al. Carnitine metabolism during exercise in patients on chronic hemodialysis. Kidney Int 41: 1613, 1992.

12. Kuwajima M, Fujihara $H$, Sei $H$, et al. Reduced carnitine level causes death from hypoglycemia. Endcr J 54: 911-925, 2007.

13. Trovato GM, Iannetti E, Murgo AM, et al. Body composition and long-term levo-carinitine supplementation. Clin Ter 149: 209, 1998.

(C) 2016 The Japanese Society of Internal Medicine

http://www.naika.or.jp/imonline/index.html 